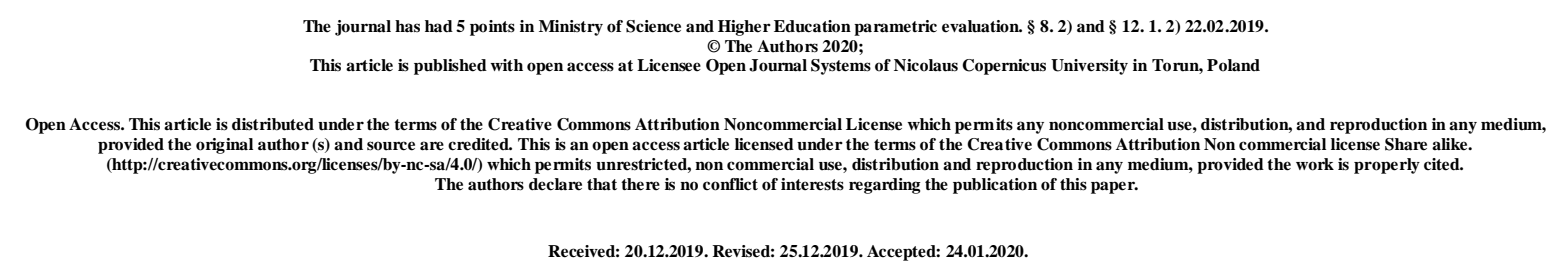

UDC: 159.972

\title{
DYSPHORIC VARIANT FORMATION OF POST-TRAUMATIC STRESS DISORDER IN COMBS
}

\section{Semenenko Kateryna Myhailivna}

\author{
Mykola Pirogov Vinnytsya National Medical University, \\ department of psychiatry, narcology and psychotherapy with a course of postgraduate \\ education (St., Pirogova, 109, Vinnytsia, Ukraine, 21005)
}

post-graduate student of the department of psychiatry, narcology and psychotherapy with the course of postgraduate education of VNMU named after M. I. Pirogov; +38 (067) 1878170; katyasemenenko88@gmail.com; https://orcid.org/0000-0002-3669-4329

\section{Abstract}

Nowadays, more combatants are suffering from the effects of an extreme event in the war zone. Specific mental trauma leads to psychiatric disorders that have common characteristics, which allows them to be separated into a separate heading - F43.1 (PTSDpost-traumatic stress disorder) in MKH-10. It is revealed that more than $26.5 \%$ of fighters from 324 respondents who returned from the ATO zone have clear signs of dysphoric variant of PTSD, including flashbacks, emotional numbness, unmotivated vigilance, maladaptation, and psychosomatic disorders. It is important to determine the criteria for the distribution of this condition, which is essential for the treatment and resolution of social issues. The purpose of the work is to identify the etiological factors and characteristic manifestations of dysphoric 
variant of PTSD in combatants. Materials and methods: On the basis of the Vinnitsa Regional Clinical Hospital of War Veterans (VRCHWV), as well as on the basis of the expert department of the scientific research institute of rehabilitation of the of disabled people of Mykola Pirogov VNMU (SRIRDP) surveyed 86 respondents suffering from dysphoric variant of PTSD. Basic methods of research: clinical anamnestic, clinical psychopathological (clinical interview), socio-demographic (questionnaire), psychodiagnostic, statistical. The results showed a significant correlation between the personal differential indices and the assessment of the level of neuro-psychic stability according to Pearson and Spearman correlation coefficients $(\mathrm{P}<0.01)$. Almost all respondents showed high and medium levels of self-esteem (6.4 and $92.3 \%$ respectively). According to the results of the surveys, the arithmetic mean of the assessment of neuropsychiatric resistance $(25.62 \pm 11.62)$ indicates a tendency for neuropsychiatric breakdowns. Conclusions: The relevance of anxiety level research is related not only to its high prevalence in patients, but also with the tendency to chronicize the process and fix symptoms in the form of persistent personality changes. Timely identification of problems will improve the effectiveness of the respondents' medical work.

Key words: dysforia; post-traumatic stress story; combatants; anti-terrorist operations.

\section{Introduction}

In the past few years, psychiatric disorders have increased significantly among combatants who have already gone to war in the anti-terrorist operation (ATO) in eastern Ukraine, including the emergence of a dysphoric variant of post-traumatic stress disorder (PTSD). Many researchers confirm that a number of professions have an impact on human activity in extreme conditions. These include work in sensory isolation, that is, in a socially impoverished environment. But it is impossible not to say about the link between various long-term stressful influences, such as being at war. Participants in various expeditions are also affected by this stress factor. The need for a long time to work in isolation from home, from family, in conditions of a limited circle of communication, information insufficiency all this is a common feature that affects the mental state of patients in the future [8, 9, 22, 23].

There is no disease, the main manifestation of which would be dysphoria. The reasons for it are quite diverse, as the dysphoric symptom complex, it is observed most often in organic brain lesions. It is necessary to take into account that changes in the brain of combatants today are caused by pathological abnormalities in the immune response and, in this connection, the pathogenesis of many diseases can be significantly associated with 
impaired cytokine production [4, 10, 22]. Many researchers have shown that cytokine deficiency contributes to the development of several diseases [3, 7, 10, 19-21]. They are endogenous mediators that regulate the duration and intensity of the immunoinflammatory response in the body $[2,3,7,20,21]$. Important is the fact that most cytokines are not only endogenous regulators of immune responses, but also key factors that induce inflammatory responses and acute-phase responses to the body can have an immunopathological effect on cells and tissues. Normally, cytokines interact with nonspecific resistance of the body and specific protection $[2,20,21]$. Their normal level makes it possible to increase the body's resistance to infections. The peculiarity of cytokines is that they themselves cannot exert influence on foreign antigens and serve solely to transmit information from one immune cell to another. Therefore, without the involvement of cytokines, the development of a normal immune response is impossible. Under different influence of immunocompetent cells and cytokines occurs activation of processes in disorders of the mental sphere. In this regard, pathogenetic correction of immunological status due to effects on the nervous system is justified $[6,24]$.

Researchers have found changes in the expression of cytochrome P450 2E1 (CYP2E1) in a human body that has experienced psycho-emotional stress. It has been shown to reduce the content of the enzyme that did not return to normal even after the cancellation of the stressor. The CYP2E1 protein is one of the isoforms of the microtome cytochrome P450, which is directly involved in the biotransformation of lipophilic substances as endogenous and exogenous in origin. It is believed that one of the most likely causes of disorders in psycho-emotional state may be oxidative stress, which develops at the cellular level under the action of various stressors. It has been shown that CYP2E1 plays a key role in these processes, enhancing activity of which may contribute to the development of oxidative stress [27]. At the same time, under conditions of oxidative stress, the intensification of peroxide processes causes changes in intracellular metabolism, which in turn changes the expression of the enzyme in the cell [26]. In some cases, oxidative stress is used by the body as a protective mechanism. The human immune system uses oxidative stress to fight pathogens, and some active forms of oxygen can serve as mediators in cellular signaling pathways.

In addition, dysphoria was often observed in combatants with various addictions, as well as in patients who had poor social conditions, grew up in asocial families, or endured episodes of violence of different nature as a child.

For the emergence of dysphoria was characterized by dissatisfaction with others, events. The beginning is often sudden. The duration varied within a range from hours or days to 
several weeks. The dysphoric episode ended, both on its own, and suddenly, the symptoms simply stopped, and in the treatment - more gradually. Prolonged dysphoric episodes in most cases also end slowly. Dysphoric status is a contributing factor to various wrongdoing and suicidal episodes.

The dysphoric variant of PTSD is manifested is manifested in various degrees [5]. Symptoms of mild degree were expressed vaguely and did not interfere with the daily life of the combatant, in most cases they can be considered peculiarities of character. These symptoms included: excessive offensiveness, irritability, stupidity, cynicism. These manifestations extended to all spheres of the individual's life, or concerned only individual events and personalities. But the expressed degree had a characteristic sad-malicious color of dysphoria. Symptoms are accompanied by fear, hopelessness, despair, expressed anxiety, constant experiences of inner frustration, tension and insomnia. A special symptom of reexperiencing the stressor was the presence of flashbacks. Manifestations of vicious episodes reached the level of agility, outbreaks of aggression. At the same time, they had spontaneous ideas and memories of a traumatic psycho-traumatic situation in the form of nightmarish dreams (often scenes of violence with the active participation of the patient). The expressed degree of dysphoria was characterized by the presence of motor excitement, inattention of patients $[17,23]$.

From the outside, combatants looked gloomy, mimicry with a tinge of discontent and irritability, and demeanor. Avoiding behavior, seclusion, and insensitivity were typical. Patients actively did not complain, but fell into the field of view of specialists in relation to behavioral disorders, which were noted by relatives or colleagues or the doctor.

Regarding the dysphoric variant of PTSD against the background of organic brain lesions, the primary sign is the increase of sensitivity to all types of stimuli (sound, light, touch), senestopathy, frequent headaches, feelings of internal tension $[5,14,17]$.

According to the 10th International Classification of Diseases, Section F 43 "Response to Severe Stress and Adaptation Disorders" distinguishes the heading: F 43.1 Post-traumatic stress disorder, which occupies a leading position in impaired respondents' mental functions in the future, because they do not occur immediately and lead to deterioration patients' lives in the form of temporary disability or even further disability of such patients $[11,25]$.

Purpose of the research: to identify characteristic etiological factors and clinical manifestations of dysphoric variant of PTSD in ATO participants on the basis of complex analysis of clinical and psychopathological, psychological and socio-demographic methods. 
Materials and methods: The main research methods were: clinical-anamnestic, clinical-psychopathological, psychodiagnostic, socio-demographic, statistical [16].

Clinical-psychopathological, clinical-anamnestic methods were based on conventional approaches to the psychiatric examination of patients.

Psychodiagnostic researches were carried out in order to evaluate the peculiarities of disturbances of functioning of emotional-volitional sphere, actual mental status. The following pathopsychological techniques were used: determination of personal differential (OD); the method of assessment of the level of neuro-mental stability "Prognosis" [1, 12, 13, $15,18,19]$.

The socio-demographic method was used to analyze the influence of various factors on the formation of dysphoric variant of PTSD in combatants.

The examination of patients was carried out on the basis of all clinical departments of the Vinnytsia Regional Clinical Hospital of War Veterans (RCHWV), as well as on the basis of the expert department of the research institute of rehabilitation of the disabled people of the Pirogov National Medical University (RIRDP). Passport data, social status, data on the mental status of patients, the extent of the manifestation of psychopathological symptoms, features of the course of the underlying and comorbidities were recorded in a specially designed form for studying the mental disorders of the dysphoric variant of PTSD in ATO participants [12, 13, 15, 17-19].

324 respondents were surveyed. The dysphoric variant of PTSD was manifested in 86 combatants: 41 patients of VOKHVV and 45 patients of NIDIR. At the time of the examination, the mean age of the patients was $44.60 \pm 1.52$ years. All surveyed participants were informed of their informed consent.

A statistical analysis of the results was carried out using Microsoft Excel 5.0. and Pearson and Spearman correlation coefficients.

\section{Results and Discussion:}

According to the results of psychodiagnostic research, which was to identify the main causes and clinical manifestations of dysphoric variant of PTSD military personnel, we used the appropriate psychodiagnostic tools that made the following conclusions.

\section{Research on the method of determining the personal differential.}

The arithmetic mean of the "evaluation" factor of the study group was $5.69 \pm 0.92$ points, which indicates the average level of self-esteem. 
Respondents' awareness of the development of their own strong-willed personality traits according to the indicators on the factor "strength" is $4.7 \pm 1,09$ points, which indicates a low level of self-control and a high dependence on external circumstances.

The average activity factor is $4.56 \pm 0.74$ points, which is interpreted as the normal level of activity, communication, impulsivity.

The arithmetic mean of the integrated self-esteem parameter is $4.96 \pm 0.7$ (Table 1).

The results of the Personal Differential technique indicate the level of self-esteem, the development of volitional qualities and the tendency to extraversion or introversion.

Table 1. Results of the study by the method of Personal Differential

\begin{tabular}{|l|l|l|l|l|}
\hline \multirow{2}{*}{$\begin{array}{l}\text { Options / } \\
\text { categories }\end{array}$} & \multirow{2}{*}{ Average value } & \multicolumn{4}{|l|}{ Distribution of respondents } \\
\cline { 3 - 5 } & & low & average & high \\
\hline rating & $5.69 \pm 0.92$ & $0 \%$ & $50 \%$ & $50 \%$ \\
\hline force & $4.7 \pm 1.09$ & $5,1 \%$ & $82,1 \%$ & $12,8 \%$ \\
\hline activity & $4.56 \pm 0.74$ & $2,6 \%$ & $94,8 \%$ & $2,6 \%$ \\
\hline self-esteem & $4.96 \pm 0.7$ & $1,3 \%$ & $92,3 \%$ & $6,4 \%$ \\
\hline
\end{tabular}

Noteworthy is the fact that when tested by the method of determining the personal differential, $1.3 \%$ of respondents gave themselves a low self-esteem. It testifies to the critical attitude of the person to himself, to insufficient level of perception of himself, to dissatisfaction with his own behavior, dependence on external circumstances, insufficient self-control; for possible asthenisation, anxiety, seclusion and inactivity. Continuous supervision of such persons is necessary because of the possible presence of certain problems related to the feeling of low value of their personality and further formation of a expressed degree of dysphoric variant of PTSD.

The high and medium levels of self-esteem were shown by $6.4 \%$ and $92.3 \%$, respectively. This indicates that they perceive themselves as self-satisfied, attribute positive, socially-approved qualities, and are characterized by independence, activity, impulsiveness, communicativeness, a tendency to overcome obstacles on their own and do not see any obvious symptoms of dysphoria.

No dependence of self-esteem level on socio-demographic parameters. 


\section{Research on the method of assessment of neuro-mental stability.}

The arithmetic mean of the evaluation of neuropsychiatric resistance is $25.62 \pm 11.62$, which indicates a tendency for neuropsychiatric breakdowns (Table 2).

Table 2. The results of the study on the method of assessment of neuro-mental stability

\begin{tabular}{|c|c|c|c|c|}
\hline \multirow{2}{*}{\begin{tabular}{c}
\multirow{2}{*}{$\begin{array}{c}\text { Options / } \\
\text { categories }\end{array}$} \\
Average \\
value
\end{tabular}} & \multicolumn{3}{|c|}{$\begin{array}{c}\text { Distribution of respondents by likelihood of } \\
\text { neuropsychiatric breakdowns }\end{array}$} \\
\cline { 3 - 5 } & unlikely & $\begin{array}{c}\text { probable under } \\
\text { extreme } \\
\text { conditions }\end{array}$ & high probability \\
\hline $\begin{array}{l}\text { Nervous and } \\
\text { psychic stability }\end{array}$ & $5.69 \pm 0.92$ & $14,1 \%$ & $48.7 \%$ & $37.2 \%$ \\
\hline
\end{tabular}

According to the results of the method of assessment of the level of neuro-mental stability the following indicators were revealed:

- $37.2 \%$ of respondents have a high likelihood of neuropsychiatric breakdowns; they require additional clinicopsychopathological examination;

- $48.7 \%$ of neuro-psychiatric breakdowns are possible, especially in extreme conditions,

- and only $14.1 \%$ of neuro-psychic breakdowns are unlikely.

A significant correlation was found between the indices of determination of the personal differential and the assessment of the level of neuro-mental stability according to the Pearson and Spearman correlation coefficients $(\mathrm{P}<0.01)$.

Also, no dependence of the likelihood of neuropsychiatric disruptions on sociodemographic parameters was detected.

\section{Conclusions and prospects for further development:}

According to the literature review, there is no clear idea about the algorithm of clinical psychodiagnosis of dysphoric PTSD disorder in victims of ATO and this issue needs further study. Therefore, it is advisable to highlight the features of psychodiagnostic support for such patients in the clinic, depending on their clinical features.

1. Chronic personality disorders, different etiological factors in combatants due to a traumatic event are complex transnological entities, characterized by persistent and longlasting relevance of psychogenically formed symptoms, reflecting stressful events. Depending on the type of dominant affect, a certain type of PTSD and chronic personality disorders are 
formed as a result of the catastrophes and the characteristics of the symptoms that determine the choice of therapeutic tactics.

2. The severity of PTSD symptoms was found in $26.5 \%$ of participants in the ATO zone. All PTSD subjects studied are divided into 2 groups: the first group includes persons in whom PTSD symptoms appear to be insignificant - 64\%; in the second group (36\%), the signs of PTSD are characterized by severe severity, which in the future require additional medical and psychological examination and support.

3. Almost all respondents showed high and medium levels of self-esteem (6.4 and 92.3\% respectively). No dependence of self-esteem level on socio-demographic parameters.

4. The arithmetic mean of the assessment of neuropsychiatric resistance (25.62 \pm 11.62$)$ indicates a tendency for neuropsychiatric breakdowns. A significant correlation was found between the indices of determination of the personal differential and the assessment of the level of neuro-mental stability according to the Pearson and Spearman correlation coefficients ( $\mathrm{P}<0.01)$. No dependence of the likelihood of neuropsychiatric disruptions on sociodemographic parameters was found.

5. Thus, the victims of the ATO at this stage there are violations of the affective sphere. And the transition of dysphoric PTSD disorder to personality disorder will be related to the personality traits and features of the social readaptation of the respondents.

6. The results of our proposed algorithm of psychodiagnostic research reflect the structure of changes in the affective sphere and certain personal predispositions in patients with dysphoric variants of PTSD.

Further research in this direction will expand the existing concepts of the causes, role and clinic of dysphoric variant of PTSD in combatants who were in the ATO zone not only for physicians, psychiatrists, but also for family medicine doctors who first meet.

\section{Reference:}

1. Alexandrova AA. Psychodiagnosis and psychocorrection. - St. Petersburg: Peter, 2016. - P. 384 (in Ukrainian)

2. Aleksandrova YN. About the system of cytokines [Text] / Yu. N. Aleksandrova // Pediatrics. - 2007. - Volume 86, No. 3. - S. 124-128 (in Russian)

3. Berezhnaya NM. Immunological studies in the clinic: state of the issue [Text] / N. M. Berezhnaya // Immunology. - 2006. - No. 1. - P. 18-23 (in Russian)

4. Berezhnaya NM. Cytokine regulation in pathology: rapid development and inevitable issues [Text] / N. M. Berezhnaya // Cytokines and inflammation. - 2007. - T. 6, No. 2. - S. 26-34 (in Russian) 
5. Voloshin PV. Post-traumatic stress disorders: problems of treatment and prevention / P. V. Voloshin, L. F. Shestopalova, V.S. Podkorytov // International Medical Journal. - 2004. - T. 10, No. 1. - S. 34-37 (in Russian)

6. Goldberg ED. Dynamic theory of blood formation regulation and the role of cytokines in the regulation of hematopoiesis [Text] / Goldberg E. D., Dygay A. M., Zhdanov V. V. // Med. immunology. - 2001. - No. 4. - S. 487-497 (in Russian)

7. Drannik GN. Clinical immunology and allergology [Text] / G. N. Drannik. Kiev, 2010 .- S. 547 (in Russian)

8. Zavrotsky VM. Analysis of peculiarities of actual psychological state of servicemen / Zavrotsky VM, Sychinska MA, Ratsiborinskaya-Polyakova NV / Proceedings of the XI International Student Scientific Conference "The First Step into Science", 2014. - Pp. 194 - 195 (in Ukrainian)

9. Kokhanov VP. Psychiatry of disasters and emergencies / VP. Kokhanov, VN. Krasnov. - M.: Practical medicine, 2008 - S. 448 (in Russian)

10. Markelov EV. The pathogenetic role of disorders in the cytokine system in infectious inflammatory diseases [Text] / E. V. Markelov, A. V. Kostyushko, V. E. Krasnikov // Pacific honey. Journal. - 2008. - No. 3. - S. 24-29 (in Russian)

11. International Classification of Diseases of the 10th revision (ICD-10). Geneva: World Health Organization, 1995. (in Russian)

12. Methodical recommendations for conducting clinical and psychological studies of the flight crew and aviation personnel involved in the participation in the IMO at the passing of medical and flight examination / Ratsiborinskaya-Polyakova NV, Konarskaya TI, Halmatova LA / "Methodological Recommendations for Clinical and Psychological Investigation of Flight Staff and Aviation Personnel Involved in Participating in the IMO when Passing Medical and Flight Examination" - for official use of the WCCC ", 2010. - P. 132 (in Ukrainian)

13. Nakonechny VM, Marusyak DA, Ratsiborinska NV, Tkach VV, Shevaga IM. Social Aspects of Diagnostics and Likewise on an outpatient basis // Materials of the scientific-practical conference "Biopsychosocial Aspects of Health" (13-14 Zhovtnya 2005.), 2005. - P. - 47-50 (in Ukrainian)

14. Post-traumatic stress disorders: diagnosis, treatment, rehabilitation: guidelines / guidelines. : Voloshin PV, Shestopalova LF, Podkorytov VS and others. - Kharkiv, 2002. - P. 47(in Ukrainian) 
15. Ratsiborinskaya NV. Modern aspects of clinical and psychological examination. Biopsychosocial Relations in the Development of Somatic Psychology // Abstracts of the Scientific and Practical Conference "The Status and Prospects of Development of Aviation Medicine" (June 10-11, 2003), 2003. - P.17-18(in Ukrainian)

16. Ratsiborinskaya NV, Kostyushin VV. The place of clinical and psychological examination in the medical support system of the Air Force of Ukraine // IX Congress of the World Federation of Ukrainian Medicinal Societies, dedicated to the 25th anniversary of SPULT: Abstracts, 2002. - P. 50 (in Ukrainian)

17. Ratsiborinskaya NV, Kostyushin VV, Khomenko VY, Kolosov AB Methodical recommendations for conducting a psychological examination of the personnel of the Air Force of Ukraine // Methodical recommendations for doctors, psychophysiologists, psychologists responsible for educational work in military units. - for official use of the Air Force of the Armed Forces of the Armed Forces, 2013. - P. 32 (in Ukrainian)

18. Ratsiborinskaya-Polyakova NV. Features of clinical psychodiagnosis of combatants / Sychinskaya MA, Savelyeva OM, Semenenko KM, Khomenko VY / Proceedings of the 13th International Scientific Conference of Students and Young Scientists « The first step into science ", Vinnitsa, 2016. - P. 30 (in Ukrainian)

19. Rimshaya SV, Ratsiborinskaya-Polyakova NV, Konarskaya TI. Psychodiagnostics as a prerequisite for organizing work with mental disadaptation // Proceedings of the scientific-practical conference "Innovative methods of diagnostics and treatment of mental and somatic disorders of psychogenic origin", 2014 (in Ukrainian)

20. Simbirtsev AS. Cytokines: classification and biological functions [Text] / A. S. Simbirtsev // Cytokines and inflammation. - 2004. - No. 2. - S. 16-22. (in Russian)

21. Simbirtsev A.S. Cytokines - a new system of regulation of protective reactions of the body [Text] / A. S. Simbirtsev // Cytokines and inflammation. - 2002. - No. 1. - S. 9-16 (in Russian)

22. Modern diagnostics and treatment in neurology and psychiatry / Ed. TS Mishchenko, VS Pidkoritova. - K .: Doctor-Media LLC, 2008. - P. 624 (in Ukrainian)

23. Tarabrina NV. Workshop on the psychology of post-traumatic stress / Tarabrina N.V. - St. Petersburg. : Peter, 2001 .- S. 272 (in Russian)

24. Shvydchenko IN. Cytokine-secreting function of neutrophilic granulocytes [Text] / I. N. Shvydchenko, I. V. Nesterova, E. Yu. Sinelnikov // Immunology. - 2005. - No. 1. - P. 31-34 (in Russian) 
25. Shestopalova L. F. Prevention of post-traumatic stress disorders in victims of suprasubic heights: medical and psychological aspects / L.F. Shestopalova // Humanitarian Chronicle. - 2005. - No. 1. - S. 103 -10 (in Ukrainian)

26. Lyakhovich VV, Vavilin VA, Zenkov NK, Menshchikova EB. Activated oxygen metabolites in monooxygenase reactions // Bull. SB RAMS. - 2005, -118, No. 4 - S. 7-12 (in Russian)

27. Tanaka E., Terada M., Misawa S. Cytochrome P450 2E1: its clinical and toxicological role // J. Clin. Pharm. Therap. - 2000. - 3, № 25. - P. 165-175 (in English)

Financing: own funds. The research was performed within the research department of the department of psychiatry, narcology and psychotherapy with a course of postgraduate education of Pirogov Vinnitsa National Medical University (PVNMU) "Scientific substantiation of diagnostic and therapeutic rehabilitation measures for endogenous and exogenously-organic psychotic and non-psychotic psychiatric disorders". (State registration number 0197U003347, 2013-2018)

\section{Conflict of interest: none.}

\section{Contribution of co-authors to the printed work:}

Semenenko Kateryna Myhailivna - owns the idea and the corresponding name, conducting psychodiagnostic techniques, monitoring their performance, searching for literature data, generalizing the results obtained, typing and editing text. 